\title{
3C-SiC-on-Si MOSFETs: overcoming material technology limitations
}

\author{
A. Arvanitopoulos, M. Antoniou, F. Li, M. R. Jennings, S. Perkins, K. N. Gyftakis and N. Lophitis
}

\begin{abstract}
The cubic polytype (3C-) of Silicon Carbide (SiC) is an emerging semiconductor technology for power devices. The featured isotropic material properties along with the Wide Band Gap (WBG) characteristics make it an excellent choice for power Metal Oxide Semiconductor Field Effect Transistors (MOSFETs). It can be grown on Silicon (Si) substrates which is itself advantageous. However, the allowable annealing temperature is limited by the melting temperature of $\mathrm{Si}$. Hence devices making use of $3 \mathrm{C}-\mathrm{SiC}$ on $\mathrm{Si}$ substrate technology suffer from poor or even almost negligible activation of the p-type dopants after ion implantation due to the relatively low allowable annealing temperature. In this paper, a novel process flow for a vertical 3C-SiC-on-Si MOSFET is presented to overcome the difficulties that currently exist in obtaining a pbody region through implantation. The proposed design has been accurately simulated with Technology Computer Aided Design (TCAD) process and device software. To ensure reliable prediction, a previously validated set of material models have been used. Further, a channel mobility physics model was developed and validated against experimental data. The output characteristics of the proposed device demonstrated promising performance, what is potentially the solution needed and a huge step towards the realisation of 3C-SiC-on-Si MOSFETs with commercially grated characteristics.
\end{abstract}

Index Terms - MOSFETs, 3C-SiC-on-Si, TCAD, SRIM, Silicon Carbide, Wide Band Gap

\section{INTRODUCTION}

$\mathrm{S}$ ilicon Carbide ( $\mathrm{SiC}$ ) is a wide band gap (WBG) semiconductor material with superior material characteristics compared to silicon $(\mathrm{Si})$. Due to that, devices based on this material are expected to replace their $\mathrm{Si}$ counterparts in power electronic applications. These WBG properties include at least two times wider energy bandgap, an order of magnitude higher critical electric field $\left(\mathrm{E}_{\mathrm{cr}}\right)$ and largely improved thermal conductivity.

$\mathrm{SiC}$ can be polymerized in numerous polytypes,

A. Arvanitopoulos, Faculty of Engineering, University of Nottingham, Nottingham, UK (e-mail: a.e.arvanitopoulos@ieee.org).

M. Antoniou, School of Engineering, University of Warwick, Coventry, UK (e-mail: ma308@cam.ac.uk).

F. Li, School of Engineering, University of Warwick, Coventry, UK (e-mail: f.li.3@warwick.ac.uk).

M. R. Jennings, College of Engineering, Swansea University, Swansea, UK (e-mail: m.r.jennings@ @swansea.ac.uk).

S. Perkins, Faculty of EEC at Coventry University, Coventry, UK (email: perkin19@uni.coventry.ac.uk).

K. N. Gyftakis, School of Engineering, University of Edinburgh, UK, (e-mail: k.n.gyftakis@ieee.org).

N. Lophitis, Faculty of Engineering, University of Nottingham, Nottingham, UK (e-mail: neo.lophitis@nottingham.ac.uk). nonetheless only one cubic (3C-) phase of $\mathrm{SiC}$ exists. The isotropic characteristics of $3 \mathrm{C}-\mathrm{SiC}$ [1][2] in conjunction to its remarkable thermal conductivity makes it a prime option for WBG power devices. The cubic $\mathrm{SiC}$ can be hetero-epitaxially grown on Si substrates using CVD [3]. This enables for large $3 \mathrm{C}-\mathrm{SiC}$-on-Si crystals, that match the diameters of commercially available $\mathrm{Si}$ wafers [4]. In consequence, discrete power devices of reduced cost can be obtained. Furthermore, the interest in the monolithic integration of $\mathrm{SiC}$ devices with $\mathrm{Si}$ technology makes the $3 \mathrm{C}-\mathrm{SiC}$ an excellent WBG semiconductor for power devices.

The $3 \mathrm{C}-\mathrm{SiC}$ is particularly promising for MOSFETs, in spite of its smaller bandgap compared to the two other major hexagonal $\mathrm{SiC}$ polytypes (4H-, 6H-) [5]. Indeed it has been shown that a 3C-SiC MOS-based switch can achieve less switching losses compared to a $4 \mathrm{H}-\mathrm{SiC}$ MOS-based switch with the same blocking capabilities [6]. Further, its smaller critical electric field value is beneficial for high frequency MOSFETs [7]. Notably, due to the narrower bandgap energy window of $3 \mathrm{C}-\mathrm{SiC}$, the majority of the observed $\mathrm{SiO}_{2} / \mathrm{SiC}$ interface trap are energetically located in the conduction band $\left(E_{C}\right)$, essentially improving the effective channel mobility [8]-[11].

Both vertical and lateral 3C-SiC-on-Si power MOSFETs have been developed and characterized in the literature [12][17]. However, they are not commercialized yet because of the high planar defects density in the 3C-SiC grown layers originating from the hetero-interface to $\mathrm{Si}$ during growth [18]. Currently, this is the main bottleneck for the 3C-SiCon-Si material technology that hinder its anticipated device performance potential.

It has been demonstrated that the density of the $\mathrm{SiO}_{2} / 3 \mathrm{C}$ SiC-on-Si interface states $\left(\mathrm{D}_{\mathrm{it}}\right)$ heavily depends on the quality of the initial epilayer [19]. The volume of the formed planar defects can be reduced when $3 \mathrm{C}-\mathrm{SiC}$ is grown on undulantSi substrates [4]. In [5], MOS capacitors fabricated on a 3CSiC-on-Si surface after ultra-violet (UV) irradiation/ozone cleaning, had their $\mathrm{SiO}_{2} / \mathrm{SiC}$ interface properties greatly improved. It is also reported that a shallow Nitrogen $(\mathrm{N})$ implantation at the gate oxide region prior to the thermal oxidation reduces the $\mathrm{D}_{\mathrm{it}}$ [20]. Therefore, improvements of the $3 \mathrm{C}-\mathrm{SiC}$ heteroepitaxy set the premises on delivering significantly more reliable MOS structures.

Interestingly, one of the $3 \mathrm{C}-\mathrm{SiC}$ beneficial properties, the ability to grow on cheap and large diameter Si substrates also 
raises another challenge for this technology in terms of p-type doping. Boron (B) and Aluminium (Al) are two of the most preferable p-type dopants for $3 \mathrm{C}$-SiC. However, the $\mathrm{B}$ is linked with the formation of deep energy levels in the $\mathrm{SiC}$ [21]. At the same time, the physical similarities of $\mathrm{Al}$ and $\mathrm{Si}$ in terms of atomic size and masses prevents lattice distortions that can act as scattering centres. Thus, $\mathrm{Al}$ is the main option for planar selective area doping for the formation of $\mathrm{p}$-type region in the $3 \mathrm{C}-\mathrm{SiC}$ material.

The Si substrate limits the activation temperature of the acceptor type implanted dopants in $3 \mathrm{C}$-SiC below its melting point. This value of approximately $1412^{\circ} \mathrm{C}$ [22] is further down compared to the required annealing temperatures of $\mathrm{Al}$, which can be as high as $1700^{\circ} \mathrm{C}$ for a nearly perfect activation (>95\%) [23]. In consequence, p-type regions by ion implantation is difficult to achieve.

The challenging nature of acceptor activation is also highlighted in [24], where 3C-SiC samples implanted at $850^{\circ} \mathrm{C}$ and annealed at $1200^{\circ} \mathrm{C}$ demonstrated n-type electrical behaviour. P-type behaviour was only observed when the sample was annealed at $1400^{\circ} \mathrm{C}$. Similarly, measurements in [25] demonstrated an activation level for the dopants of less than $1 \%$. Such inefficient holes' generation process demands high acceptor dopant concentration for p-type 3C-SiC which in turn induces more lattice defects deteriorating the hole mobility. This challenge can be a limiting factor for conventional 3C-SiC-on-Si MOSFET designs.

In this paper, a novel process flow is proposed for the fabrication of vertical 3C-SiC-on-Si MOSFETs which eliminates the need for $\mathrm{Al}$ implantation. This includes a homo-epitaxially grown p-layer on top of the n-drift layer, rather than formatting the p-body with multiple implants. The proposed design has been developed with the Technology Computer Aided Design (TCAD) Synopsys Process tool and its performance simulated with Synopsys Device tool. A previously validated set of physics models are used to accurately describe the 3C-SiC material which was previously published in [26], [27]. Traps at the interface between $\mathrm{SiO}_{2} / 3 \mathrm{C}$-SiC have also been included with density values that agree with reported fabricated structures in the literature for this technology. The results in this work highlight that the proposed design is able to deliver 3C-SiCon-Si MOSFETs with excellent output characteristics.

\section{NOVEL MOSFET DESIGN AND FABRICATION METHOD}

The viability of the conventional implanted body design method, in Fig. 1, is under question for 3C-SiC-on-Si MOSFETs because of the reported challenges in the activation of p-type dopants in cubic SiC polytype [24], [25]. In an effort to address this major material-related issue, an alternative MOSFET design and fabrication methodology is proposed. Instead of forming the p-body regions by implantation, it is proposed to grow a thin 3C-SiC layer of $\mathrm{p}$ type conductivity on top of the hetero-epitaxially grown n- drift 3C-SiC layer. This can be achieved by changing the $\mathrm{SiC}$ epitaxial film growth conditions in the chamber from $\mathrm{N}$ to $\mathrm{Al}$ rich environment. Thereafter, the JFET region can be shaped with implants of high $\mathrm{N}$ concentration to overcompensate desired areas. Implanted $\mathrm{N}$ in $3 \mathrm{C}-\mathrm{SiC}$-on-Si is known to activate at low annealing temperature, which makes this a viable alternative fabrication process. Due to the resulting highly doped regions, such device cannot block significant voltage and can break prematurely. The proposed design includes novel features shown in Fig 1, which allow the mitigation from high concentration of electric fields. With the application of appropriate masks, a localised Super-Junction $(\mathrm{S}-\mathrm{J})$ is created in the form of edges extending from the body into the JFET region. They assist in largely mitigating the charge imbalance and maintain high blocking voltage capability.

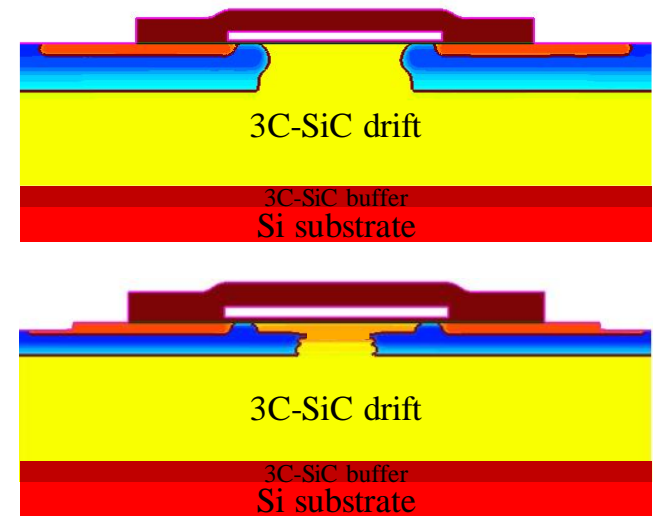

Fig. 1 The conventional implanted body MOSFET design (top) and the novel S-J JFET MOSFET design (bottom).

\section{A. Epitxially grown P-body region}

The proposed 3C-SiC-on-Si MOSFET with S-J JFET region suggests homo-epitaxy of a thin $3 \mathrm{C}-\mathrm{SiC}$ layer of $\mathrm{p}$ type conductivity on top of the hetero-epitaxially grown ndrift 3C-SiC layer. Two variants of the in-situ doped p-body region are investigated, one with gradual doping profile and another one with stepped profile.

The stepped doping profile comprises of four doping levels, which exist one after another following a step-wise pattern, as illustrated with the dashed horizontal lines in Fig. 2. Beginning from the $3 \mathrm{C}-\mathrm{SiC}$ surface and expanding up to a depth of $0.15 \mu \mathrm{m}$, a constant doping level of $N_{A}=$ $5 \times 10^{16} \mathrm{~cm}^{-3}$ is considered. Following, the second step is a constant doping level of $N_{A}=1 \times 10^{18} \mathrm{~cm}^{-3}$ characterizing the region from $0.15 \mu \mathrm{m}$ up to $0.45 \mu \mathrm{m}$. The third doping step of $N_{A}=1 \times 10^{17} \mathrm{~cm}^{-3}$ is valid up to a depth of $0.575 \mu \mathrm{m}$ from the semiconductor surface and then the fourth doping level of $N_{A}=8 \times 10^{15} \mathrm{~cm}^{-3}$ completes the stepped doping profile in the p-body at the depth value of $0.7 \mu \mathrm{m}$.

The gradual doping profile is obtained by altering gradually the concentration of acceptors during the epitaxial growth process. The gradual doping profile is illustrated with filled circular marks in Fig. 2.

Both the stepped and the gradual profiles were designed to 
be comparable and similar. Importantly they feature a retrograde profile. The p-body doping at the $3 \mathrm{C}-\mathrm{SiC}$ surface, is designed with low concentration, in the range of $1-$ $5 \times 10^{16} \mathrm{~cm}^{-3}$, to increase the controllability of the threshold voltage value within $3-5 \mathrm{~V}$. The p-body doping concentration increases with increasing depth until a peak value is reached and then drops to a minimum merit. The peak concentration needs to be high enough $\left(\sim 1 \times 10^{18}\right)$ to support high voltage and avoid punch through.

\section{B. Implanted JFET region}

The n-type JFET is formed with several $\mathrm{N}$ ion implantation of adequate levels to overcompensate the doping of the p-body. The minimum steps of $\mathrm{N}$ implants required to form the JFET, along with the corresponding implantation energies, were determined with accurate Monte Carlo simulations, utilizing the SRIM/TRIM model for 3C$\mathrm{SiC}$ target material [28]. For each independent implantation step simulated on the 3C-SiC target material, the obtained Nitrogen fluence Gaussian distribution was interpolated to a common penetration depth-axis. The combination of five implant steps with energies $110 \mathrm{keV}, 180 \mathrm{keV}, 275 \mathrm{keV}$, $375 \mathrm{keV}$ and $475 \mathrm{keV}$ was established, resulting in a doping profile with the capacity to adequately over-compensate the p-body doping for the desired depth. Considering sufficient dose values, as listed in Table I, the predicted net profile from the implanted $\mathrm{N}$ is illustrated in Fig. 2, co-plotted with the in-

Table I. Dose values for the $\mathrm{N}$ implants to form the $\mathrm{n}$ JFET doping profile in Fig. 2 based on SRIM/TRIM simulations.

\begin{tabular}{|c|c|c|c|}
\hline Target/Ion & $\begin{array}{c}\text { Implant Energy } \\
(\mathrm{keV})\end{array}$ & $\begin{array}{c}\text { Peak Fluence } \\
\left(\mathrm{cm}^{-3}\right) /\left(\mathrm{cm}^{-2}\right)\end{array}$ & $\begin{array}{c}\text { Dose } \\
\left(\mathrm{cm}^{-2}\right)\end{array}$ \\
\hline $3 \mathrm{C}-\mathrm{SiC} / \mathrm{N}$ & 110 & $1.17 \times 10^{5}$ & $1.7 \times 10^{13}$ \\
\hline $3 \mathrm{C}-\mathrm{SiC} / \mathrm{N}$ & 180 & $9.05 \times 10^{4}$ & $1.5 \times 10^{13}$ \\
\hline $3 \mathrm{C}-\mathrm{SiC} / \mathrm{N}$ & 275 & $7.86 \times 10^{4}$ & $2.3 \times 10^{13}$ \\
\hline $3 \mathrm{C}-\mathrm{SiC} / \mathrm{N}$ & 375 & $7.14 \times 10^{4}$ & $2.0 \times 10^{11}$ \\
\hline $3 \mathrm{C}-\mathrm{SiC} / \mathrm{N}$ & 475 & $6.81 \times 10^{4}$ & $9.0 \times 10^{11}$ \\
\hline
\end{tabular}

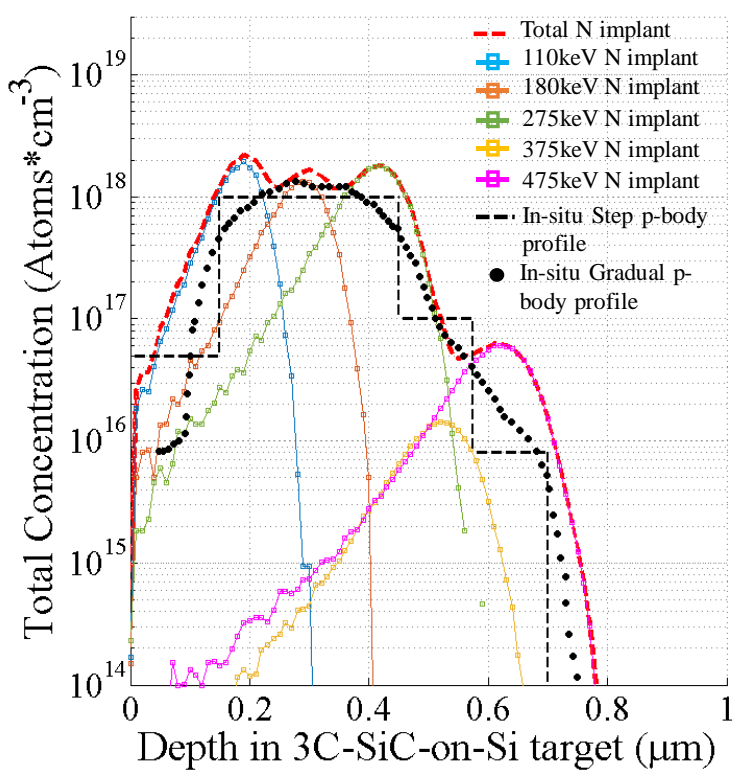

Fig. 2. The in-situ doping profiles of the p-body (both gradual and stepwise) and the total $\mathrm{N}$ implanted for the n-JFET overcompensation. situ gradual and stepped doping profiles within the p-body.

\section{Super-Junction JFET region}

The precise compensation of the homo-epitaxially grown p-body layer is a challenging task. To ensure overcompensation and the successful formation of an n-type conductivity continuous JFET region, the doses of each $\mathrm{N}$ implant should generate a concentration higher than the underlying concentration of holes. To over-compensate the highly doped p-body layers, the obtained JFET is, in turn, also highly doped. This has the potential of reducing the onresistance $\left(R_{D S, o n}\right)$ at the expense of blocking voltage degradation. To counterbalance the loss of blocking ability, the implantation of $\mathrm{N}$ is carried out through masks to form a S-J region. The proposed process, in Fig. 3, leads to the formation of edge-shaped p-type regions within the JFET, resulting in S-J JFET designs. The process steps for the proposed S-J JFET design comprise of: (a) In-situ growth of the p-body layer on the 3C-SiC-on-Si n-drift, (b1) Application of a first mask for ion implantations up to $275 \mathrm{keV}$, from Table I, to form the first stage of the n-JFET, (b2) Application of an additional mask to spatially limit the higher energy implants [29], (c) Ion implantation to form the n-source pads, (d) etching of the lowly doped surface of the p-body to reach the high concentration part of p-body. This helps suppressing the parasitic BJT, (e) oxidation for the gate oxide formation, (f) deposition of gate metal, (g) oxide deposition as an inter-layer dielectric (ILD) to isolate gate and source conductors from each other, (h) opening of the source contacts, (i) source metallization.

\section{THE IMPLANTED BODY 3C-SIC-ON-SI MOSFET DESIGN}

Although the real activation of acceptor-type implants in $3 \mathrm{C}$ SiC-on-Si is minimal, a TCAD model of such conventional MOSFET can be tuned to have equivalent activation to that of in-situ acceptor doping. The FEA simulation results for this theoretical MOSFET design can be used as reference for the direct comparison of the proposed MOSFET with S-J JFET. They also constitute the theoretical performance limit.

To create the theoretical 3C-SiC-on-Si MOSFET model according to the implanted body design method, the sProcess TCAD tool is utilized The moderately doped n-drift layer is obtained with hetero-epitaxy on an isotype Si substrate. The p-body region is formed by selective ion implantations to result in a doping profile similar to the one considered for the proposed S-J JFET designs. The net implanted profile for the p-body considering all the Al implants, as predicted by SRIM/TRIM, is illustrated in Fig. 4. The terms conventional and implanted body design method will be used interchangeably for the rest of this work.

The detailed process steps for the proposed implanted body MOSFET design comprise of: (a) Ion implantation to form the p-body with the doping profile of Fig. 4, (b) Further $\mathrm{Al}$ implantation at the source contact sides to reduce the 

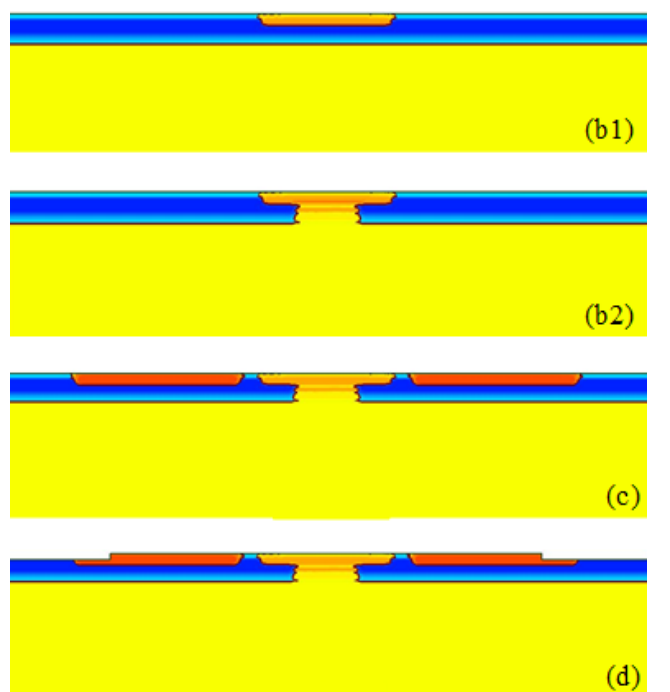

(d)
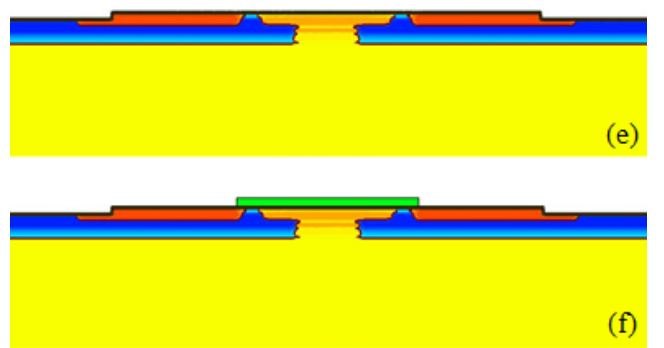

(f)
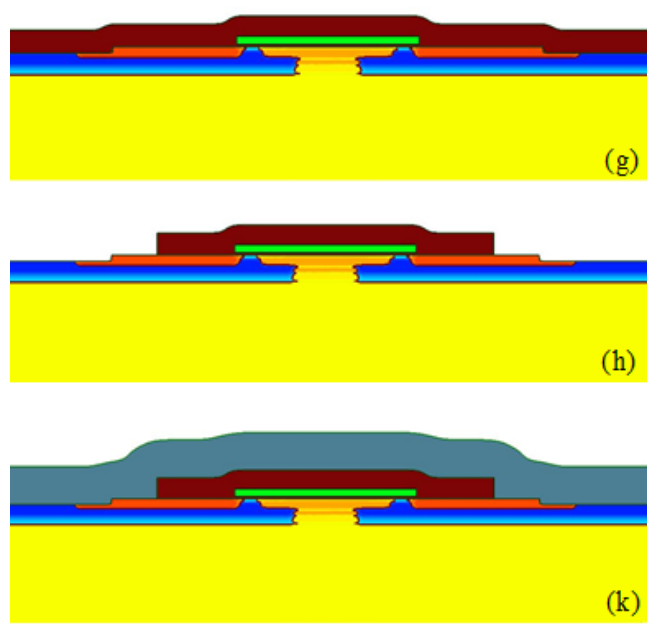

Fig. 3. Fabrication process for novel vertical MOSFET featuring S-J JFET.

possibility of parasitic BJT latch-up, (c) Ion implantation to form the n-source pads, (d) oxidation for the gate oxide, (e) deposition of gate metal, (f) oxide deposition as an ILD to isolate gate and source conductors from each other, $(\mathrm{g})$ opening of the source contacts, (h) source metallization. Simulating these process steps, the resulted implanted body MOSFET is shown in Fig. 1.

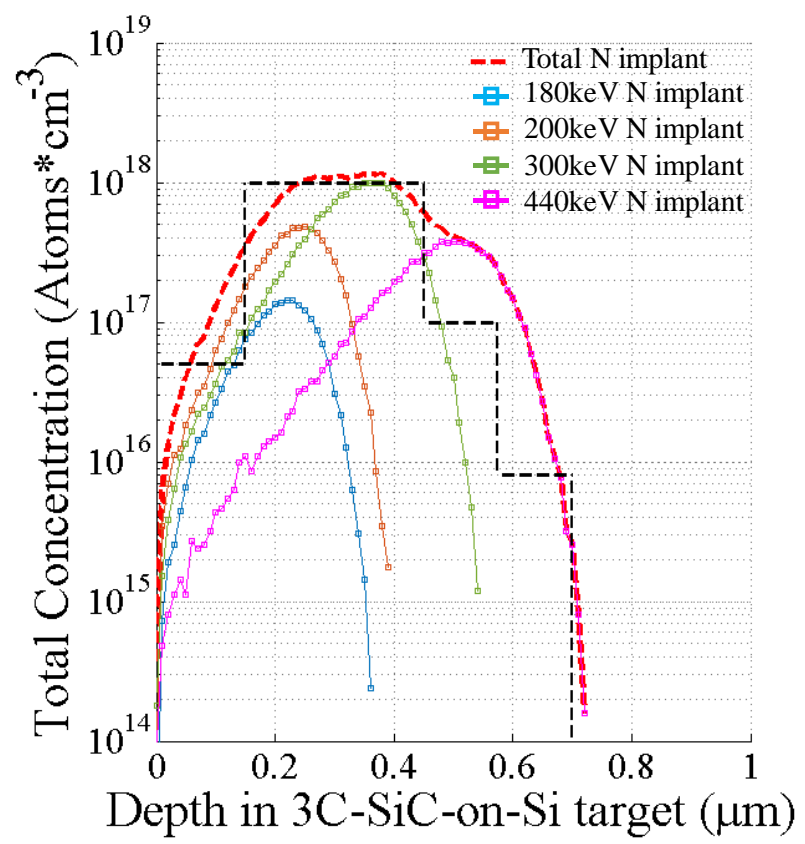

Fig. 4. The total Al implants considered for the implanted body of a conventional 3C-SiC-on-Si MOSFET design.

\section{EXPERIMENTALLY VALIDATED CHANNEL AND ACCUMMULATION LAYER MOBILITY MODEL FOR 3C-SIC MOS STRUCTURES}

To analyse the proposed MOSFET, it is important to use models which can replicate the physical phenomena taking place within the device. The degradation of mobility at the $3 \mathrm{C}-\mathrm{SiC} / \mathrm{SiO}_{2}$ interface due to electron-phonon scattering effects is of particular importance for MOSFET performance analysis. In this section an appropriate model is presented and validated against experimental measurements. In the inversion layer of a SiC MOSFET, the high transverse electric field forces electrons to interact strongly with the $\mathrm{SiC}$-insulator interface. In turn, the channel region is considered to be among the regions that contribute the most to the resulted device on-state resistance.

According to the Matthiessen's rule (1), the mobility of the carriers within an n-type channel $\left(\mu_{c h}\right)$ results as a weighted degradation contribution due to doping level $\left(\mu_{d o p}^{3 C-S i C}\right)$, electric field $\left(\mu_{E / /}^{3 C-S i C}\right)$ and scattering phenomena. Both the $\mu_{d o p}^{3 C-S i C}$ and the $\mu_{E / /}^{3 C-S i C}$ have been accurately modelled in previous works by the authors of this paper [26], [27]. In particular, the $\mu_{E / /}^{3 C-S i C}$ degradation component is due to the electric field element parallel to the current flow. On the contrary, the transverse electric field $\left(\mu_{E^{\perp}}\right)$ is the driving force for the mobility degradation due to scattering at the semiconductor/oxide interface. The latter comprises of acoustic phonon scattering $\left(\mu_{a c}^{3 C-S i C}\right)$, surface roughness scattering $\left(\mu_{S R}^{3 C-S i C}\right)$ and Coulomb scattering with charged traps and fixed charges $\left(\mu_{c b}^{3 C-S i C}\right)$. In Matthiessen's rule, to switch off the inversion layer terms far away from the 
interface, the damping parameter $\mathrm{D}=\exp (-\mathrm{x} / \mathrm{lcrit})$ is deployed, where $\mathrm{x}$ is the actual distance from the interface.

$$
\begin{gathered}
\mu_{c h}=\frac{1}{\mu_{d o p}}+\frac{1}{\mu_{E / /}}+\frac{D}{\mu_{a c}}+\frac{D}{\mu_{S R}}+\frac{1}{\mu_{c b}} \\
\mu_{a c}=\frac{B}{E_{\perp}}+\frac{C N_{A}^{\lambda}}{E_{\perp}^{1 / 3}(T / 300)^{k_{1}}} \\
\mu_{S R}=\left(\frac{E_{\perp}^{A^{*}}}{\delta}+\frac{E_{\perp}^{3}}{\eta}\right)^{-1} \\
A^{*}=A_{\text {init }}+\frac{\left(a_{\perp, n} n+a_{\perp, p} p\right) N_{r e f}^{\beta}}{N_{A}^{\beta}} \\
\mu_{c b}=\frac{\mu_{1}\left(\frac{T}{300}\right)^{k_{2}}\left\{1+\left[n /\left(n_{\text {trans }}\left(\frac{D_{i}}{N_{0}}\right)^{\eta_{1}}\right)\right]^{v}\right\}}{\left(\frac{D_{i}}{N_{0}}\right)^{\eta_{2}} e^{-d_{\text {int }} / l_{\text {crit }} \cdot\left(1-e^{-\left(E_{\perp} / E_{0}\right)^{\gamma}}\right)}}
\end{gathered}
$$

Table II. Validated parameter values for the channel mobility in 3C-SiC MOS device concepts.

\begin{tabular}{|c|c|c|}
\hline Parameter & Scattering Type & Value \\
\hline$B\left(\mathrm{~cm} \cdot \mathrm{s}^{-1}\right)$ & $(2)$ & $5 \times 10^{8}$ \\
\hline$C\left(\mathrm{~cm}^{5 / 3} V^{-2 / 3} \mathrm{~s}^{-1}\right)$ & $(2)$ & $5 \times 10^{2}$ \\
\hline$\lambda$ & $(2)$ & 0.1 \\
\hline$k_{1}$ & $(2)$ & 5 \\
\hline$\delta\left(\mathrm{cm}^{2} V^{-1} \mathrm{~s}^{-1}\right)$ & $(3)$ & $5 \times 10^{16}$ \\
\hline$\eta\left(V^{2} \mathrm{~cm}^{-1} \mathrm{~s}^{-1}\right)$ & $(3)$ & $3 \times 10^{20}$ \\
\hline$A_{\text {init }}$ & $(4)$ & 2.1 \\
\hline$\alpha_{\perp, n}\left(\mathrm{~cm}^{3}\right)$ & $(4)$ & \multirow{2}{*}{$6.85 \times 10^{-21}$} \\
\hline$\alpha_{\perp, p}\left(\mathrm{~cm}^{3}\right)$ & $(4)$ & 1 \\
\hline$N_{\text {ref }}\left(\mathrm{cm}^{-3}\right)$ & $(4)$ & $92 \times 10^{-3}$ \\
\hline$\beta$ & $(4)$ & $1 \times 10^{-6}$ \\
\hline$E_{0}\left(V \mathrm{Vm} \mathrm{m}^{-1}\right)$ & $(5)$ & $1 \times 10^{11}$ \\
\hline$N_{0}\left(\mathrm{~cm}{ }^{-2}\right)$ & $(5)$ & 1 \\
\hline$\gamma$ & $(5)$ & 1 \\
\hline$\mu_{1}\left(\mathrm{~cm}{ }^{2} V^{-1} \mathrm{~s}^{-1}\right)$ & $(5)$ & $2 \times 10^{16}$ \\
\hline$n_{\text {trans }}\left(\mathrm{cm}{ }^{-3}\right)$ & $(5)$ & 0.1 \\
\hline$\eta_{1}$ & $(5)$ & 0.4 \\
\hline$\eta_{2}$ & $(5)$ & 1.2 \\
\hline$v$ & $(5)$ & $5 \times 10^{-8}$ \\
\hline$d_{\text {int }}(\mathrm{cm})$ & $(5)$ & $7 \times 10^{-7}$ \\
\hline$l_{\text {crit }}(\mathrm{cm})$ & $(5)$ & 1.5 \\
\hline$k_{2}$ & $(5)$ & \\
\hline & & \\
\hline
\end{tabular}

The model developed for the degradation of electrons' mobility at the $3 \mathrm{C}-\mathrm{SiC} / \mathrm{SiO}_{2}$ inversion layer due to scattering according to (2)-(5) has been validated utilizing channel mobility measurements obtained from a 3C-SiC n-MOS structure featuring poly-Si as gate metal, $t_{o x}=64 \mathrm{~nm}$ of $\mathrm{SiO}_{2}$ gate oxide and a characterized $D_{i t}^{3 C-S i C}=$ $1.8 \times 10^{12} \mathrm{~cm}^{-2}$, whilst the p-body doping has been assessed $N_{A}=2.5 \times 10^{17} \mathrm{~cm}^{-3}$ [30]. The geometry of this 3C-SiC nMOS structure was accurately replicated with TCAD ensuring a fine meshing for the inversion layer. The channel was considered within $1 \mathrm{~nm}-5 \mathrm{~nm}$ from the interface between the $3 \mathrm{C}-\mathrm{SiC}$ and the $\mathrm{SiO}_{2}$ and is delimited by the parameter value lcrit. Considering $\mathrm{T}=300 \mathrm{~K}$, the driving forces $\left(E_{\perp}, E / /\right)$ and the densities of both free electrons (n) and free holes (p) at the channel region were extracted from the simulated structure and imported in MATLAB allowing a complex mathematical correlation of the parameters for (2)-(5) resulting in the values presented in Table II.

Since operation at elevated temperatures is a key feature of $\mathrm{SiC}$ devices, the developed model was expanded to predict the dependency on temperature. This dependency is described with the parameters $k_{1}$ and $k_{2}$, in (2) and (5) correspondingly, the values of which were determined utilizing channel mobility measurements at $\mathrm{T}=473 \mathrm{~K}$ from the same n-MOS structure [30].

In Fig. 5, the incorporation of the developed model in the Matthiessen's rule (1) is capable of re-producing the measured channel mobility values as both a function of the applied gate voltage and temperature.

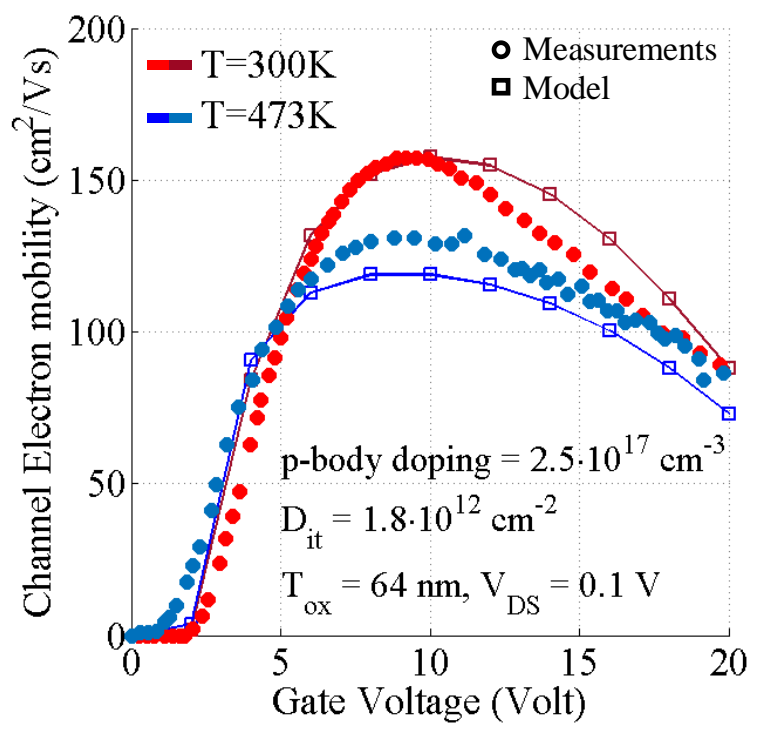

Fig. 5 The developed channel mobility model is capable of predicting the measurements obtained from the 3C-SiC n-MOS structure [30] for a wide range of gate voltage values and for different temperatures.

\section{Evaluation of The Proposed S-J JFET 3C-SiC-ON-Si MOSFET DESIGN}

Synopsys Sentaurus Device (sDevice) [31] tool has been used to simulate the electrical performance of the proposed structures (Fig. 3). Key to these simulations is the utilization of a previously developed and validated material model for bulk 3C-SiC material [21], [27]. The sProcess MOSstructures, both the S-J JFET and the implanted body designs, feature a cell pitch of $16 \mu \mathrm{m}$, whilst the drift layer is modelled $10 \mu \mathrm{m}$ thick and $5 \times 10^{15} \mathrm{~cm}^{-3} \mathrm{n}$-type doped. A highly doped buffer layer is also considered of $1 \mu \mathrm{m}$ thickness between the 3C-SiC drift and the Si substrate. The latter, is assumed to be $110 \mu \mathrm{m}$ thick and $1 \times 10^{19} \mathrm{~cm}^{-3} \mathrm{~N}$ doped. The source $\mathrm{n}+$ regions are highly doped to ensure good ohmic contacts. Moreover, positive fixed charges are modeled at the $3 \mathrm{C}-\mathrm{SiC} / \mathrm{SiO}_{2}$ interface with $D_{i t}^{3 C-S i C}=2.5 \times 10^{11} \mathrm{~cm}^{-2}$, in accordance with characterized values from the literature [5], [17].

The geometries of the simulated MOS systems were 
aimed to be identical, enabling a direct comparison of their electrical performance. Regarding the MOS interface, all the considered designs feature the same $D_{i t}^{3 C-S i C}$ and a gate oxide thickness of $t_{o x}=60 \mathrm{~nm}$. The doping profiles in the body region, for both the in-situ (Fig. 2) and the ion-implanted (Fig. 4) cases, are designated to be similar. In consequence, the implanted body and the edge S-J JFET simulated devices exhibited a threshold voltage value in the range of $V_{t h}=$ $3.2-3.7 \mathrm{~V}$. The active area of the devices considered for this work is $7.3 \times 10^{-4} \mathrm{~cm}^{2}$ and it is equivalent to the fabricated $3 \mathrm{C}$ $\mathrm{SiC}$ MOSFET in [14].

\section{A. Charge Imbalance}

To evaluate and optimise the suggested 3C-SiC-on-Si MOSFET design featuring S-J JFET, a thorough simulation study was carried out. The doses of each $\mathrm{N}$ implant step, in Fig. 2, were varied while keeping the implant energies fixed. Each time, the values of all the doses were modified in like manner, i.e. as a percentage of the initial dose values considered in Table I, to determine a new design variant for simulation. This resulted in MOSFET designs with different amount of charge within the formed S-J JFET.

The higher the dose values, the more the stored charge in the S-J regions, deteriorating the blocking capability of the body diode. Given that the charge at the p-type regions of the S-J $\left(Q_{p}^{S-J}\right)$ is constant (placed in-situ) modifying the charge of the n-type S-J JFET $\left(Q_{n}^{S-J}\right)$ essentially alters the charge balance of the body diode. This charge imbalance is critical for the performance of the proposed MOSFETs in the forward blocking mode. In consequence, the charge imbalance formula in (6) is utilized to investigate the effect of the stored charge at the n-JFET on the breakdown voltage.

$$
\text { Charge Imbalance }(\%)=\frac{Q_{p}^{S-J}-Q_{n}^{S-J}}{Q_{p}^{S-J}} \cdot 100 \%
$$

The stored charge in the $\mathrm{p}-\left(Q_{p}^{S-J}\right)$ and n-type $\left(Q_{n}^{S-J}\right)$ S-J parts is calculated for each simulated design variant by integrating the concentration of the corresponding activated dopants up to the desired depth, i.e. the depth of the JFET region, and then multiplying the outcome with the width of the region of interest. For the edge S-J JFET designs, the calculation for the charge in the n-JFET splits in two parts that is one for the upper and one for the bottom JFET region. The left and right edges are accounted for the p-type charge of the S-J.

The defined trade-off between the calculated charge imbalance (6) and the breakdown voltage, after handling the dose of each implant as variable, is shown in Fig. 6 for the proposed S-J JFET MOSFET. A transition on the X-axis from right to left indicates increased dose values for the $\mathrm{N}$ implants resulting in a more negative charge imbalance value. A fitting curve is co-plotted in Fig. 6, to illustrate the predicted behaviour, suggesting a safe window from $-65 \%$ up to $0 \%$ for the edge S-J design for a targeted $V_{B R}>500 \mathrm{~V}$. Notably, when the charge imbalance curve, in Fig. 6, approaches the $0 \%$ point, the over-compensation of the p-body is less likely to be complete. In such undesired cases, p-stripes exist in the JFET, which obstruct the free electron flow, resulting in a non-MOSFET structure characterized by an excessive resistance value.

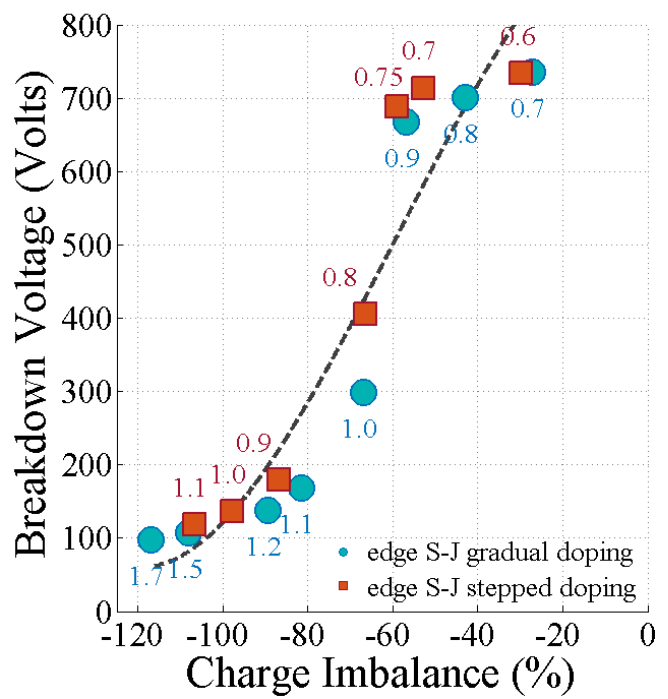

Fig. 6 The blocking voltage as a function of the charge imbalance for the simulated devices. The points annotation correspond to the percentage of the dose values listed in Table I considered for the particular design variant.

\section{B. Specific On-resistance}

The on-resistance is calculated for each simulated MOSstructure as the slope of the $I_{D}-V_{D}$ plot. The values of $V_{D}=$ $0.5 \mathrm{~V}$ and $V_{G}=10 \mathrm{~V}$ have been selected to ensure the $R_{D S \text {,on }}$ is calculated while all the simulated devices operate in the linear region. The specific on-resistance $\left(R_{D S, o n}^{S p}\right)$, is then obtained, by multiplying the calculated on-resistance with the active area of the devices. The $R_{D S \text {,on }}^{s p}$ against the blocking voltage plot, in Fig. 7, excludes the points that correspond to the design variants with a very high $R_{D S \text {,on }}^{s p}$ value due to insufficient formation of the JFET. Therefore, from both Fig. 6 and Fig. 7, the acceptable charge imbalance window is redefined from $-65 \%$ up to $-45 \%$ for the S-J JFET design.

The simulated electrical performance in Fig. 7, in terms of $R_{D S, \text { on }}^{s p}$ and breakdown voltage, is compared with the 3C-SiC unipolar limit. This curve specifies the minimum specific onresistance of unipolar devices for the corresponding blocking voltage capabilities and constitutes a widely acceptable mean to discuss on the technological maturity of the power semiconductor. The unipolar limit for $3 \mathrm{C}-\mathrm{SiC}$ is calculated with (7), as the trade-off relationship between the specific onresistance of a drift layer (forward operation mode) and the corresponding breakdown voltage (reverse operation mode) [32]. The expressions regarding the $V_{B R}^{3 C-S i C}$ and $E_{C r}^{3 C-S i C}$ derived from the Power formula for $3 \mathrm{C}-\mathrm{SiC}$ [33] as a function 
of the doping concentration, have been deployed in (7). The Power formula for $3 \mathrm{C}-\mathrm{SiC}$ and, hence, the derived expressions for the critical field and the breakdown voltage assume NPT structures for which all the drift is ideally depleted. For completeness, the unipolar limits for $\mathrm{Si}$ and $4 \mathrm{H}-$ $\mathrm{SiC}[34]$ are also plotted in Fig. 7.

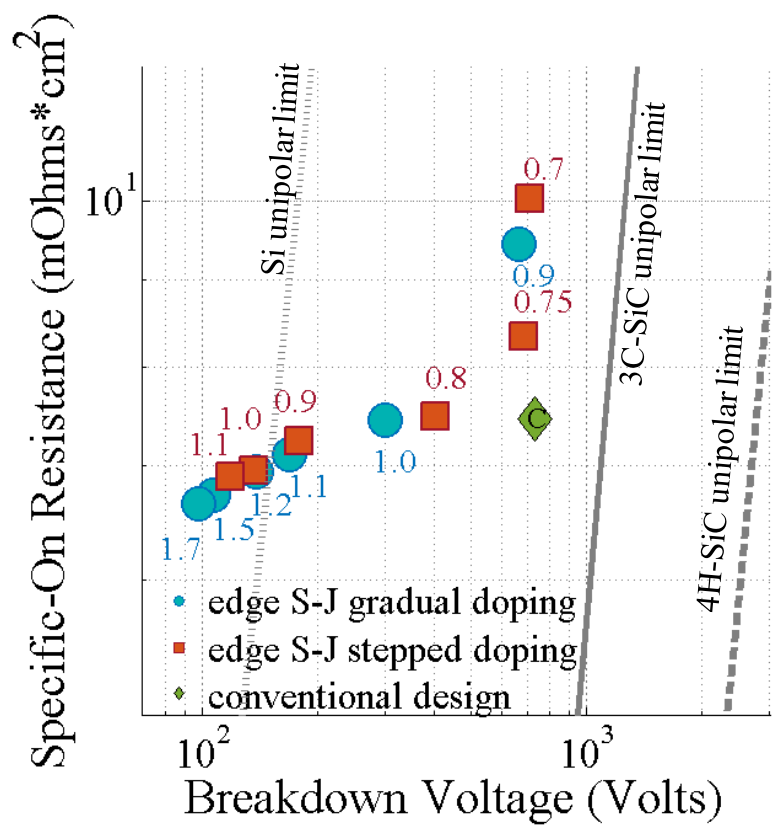

Fig. 7 The $R_{D S \text {,on }}^{s p}$ as a function of blocking voltage for the simulated devices. The points annotation correspond to the percentage of the dose values listed in Table I considered for the particular design variant.

$$
R_{D S, \text { on }}^{s p}=\frac{4 V_{B R}^{2}}{\varepsilon_{S} \mu E_{C r}^{3}}
$$

In Fig. 7, the conventional or implanted-body design method for the 3C-SiC-on-Si MOSFET demonstrates a breakdown voltage very close to the one suggested by the $3 \mathrm{C}$ $\mathrm{SiC}$ unipolar limit. However, it features a higher $R_{D S, \text { on }}^{s p}$ value. The same stands for the simulated on-state performance of the proposed S-J JFET designs. The definition of the unipolar limit explains why we should expect a larger $R_{D S, \text { on }}^{s p}$ with MOSFETs. This definition assumes the specific onresistance of a drift layer. On the contrary, the total resistance of a vertical MOS-based device, arises as the summation of the channel resistance $\left(R_{c h}\right)$, the JFET resistance $\left(R_{J F E T}\right)$, the drift layer resistance $\left(R_{\text {drift }}\right)$, the buffer layer resistance $\left(R_{b u f}\right)$ and the substrate resistance $\left(R_{\text {sub }}\right)$.

The developed model for the channel mobility shapes the $R_{c h}$ contribution by taking into account the degradation of the electrons mobility at the $3 \mathrm{C}-\mathrm{SiC} / \mathrm{SiO}_{2}$ interface. Further, both $R_{b u f}$ and $R_{\text {sub }}$ have a reduced contribution to the device resistance as highly doped regions. The JFET effect is mainly responsible for the observed deviation of the specific onresistance of the simulated MOSFETs from the 3C-SiC unipolar limit. The JFET effect induces a modified effective width for the current to flow, from the initial cell pitch value to a reduced one. This leads to a non-uniform current distribution within both the JFET and the drift regions, resulting in increased $R_{J F E T}$ and $R_{\text {drift }}$ values, which also incorporate the effect from the formed depletion region, essentially increasing the total $R_{D S, o n}^{S p}$.

\section{Performance and effectiveness of the $S$-J JFET region}

From Fig. 6 and Fig. 7, the "golden" design is identified to feature $75 \%$ of the dose values shown in Table I and with stepwise p-body doping profile. To demonstrate the effectiveness of the proposed "golden" design, the S-J region was removed by omitting the additional mask (process step b2 in Fig. 3). The electrical performance of the "non-S-J variant" was studied and compared with the "Golden design having S-J JFET". The simulated performance of the golden design summarised in Table III, suggests that the proposed SJ JFET MOSFET based on 3C-SiC-on-Si is capable of exhibiting similar forward blocking capabilities compared to a conventional method used to design MOSFETs

Considering $\mathrm{T}=300 \mathrm{~K}$, the simulated $R_{D S \text {,on }}^{s p}$ is slightly higher for the golden S-J JFET design compared to a theoretical implanted body design. This is attributed to the small number of $\mathrm{N}$ implantations used. With a larger number of implantations, the JFET profile can be further fine-tuned, leading to a MOSFET design with in-situ doped p-body having a resistance closer to the theoretical limit. At elevated temperature, the blocking capability of all variants examined increase. This is expected as the breakdown voltage in unipolar devices is determined by impact ionization induced avalanche. Since the impact ionization rates decrease when the temperature increases, the blocking voltage increases [27]. At $\mathrm{T}=473 \mathrm{~K}$, the golden design achieves blocking voltage of $790 \mathrm{~V}$. The predicted $R_{D S, \text { on }}^{s p}$ values follow the expected trend too. With increasing temperature, the $R_{D S \text {,on }}^{s p}$ increases too. Interestingly, the golden device exhibits slightly lower $R_{D S \text {, on }}^{s p}$ compared to the theoretical design at $\mathrm{T}=473 \mathrm{~K}$ whereas at $\mathrm{T}=300 \mathrm{~K}$ it was the opposite.

The golden design without S-J JFET can support only $387 \mathrm{~V}$ (at $\mathrm{T}=300 \mathrm{~K}$ ) compared to $688 \mathrm{~V}$ achieved when a S-J JFET is formed. The difference in performance is explained by studying the Electric Field distribution at 375V (Fig. 8). As shown in Fig. 8a, in the absence of S-J region the peak electric field at the corner between the p-body with the JFET region and at the bottom of the gate oxide reaches values in excess of $2 \mathrm{MVcm}^{-1}$. The high Electric Field observed causes excessive impact ionization which degrades the forward blocking capability. In comparison, when a S-J region is formed by extending the p-body edge (Fig. 8b), the Electric Field is suppressed, leading to reduced impact ionization phenomenon and therefore higher breakdown voltage. This is true both at room temperature $(\mathrm{T}=300 \mathrm{~K})$ and high temperature e.g. at $\mathrm{T}=470 \mathrm{~K}$. 

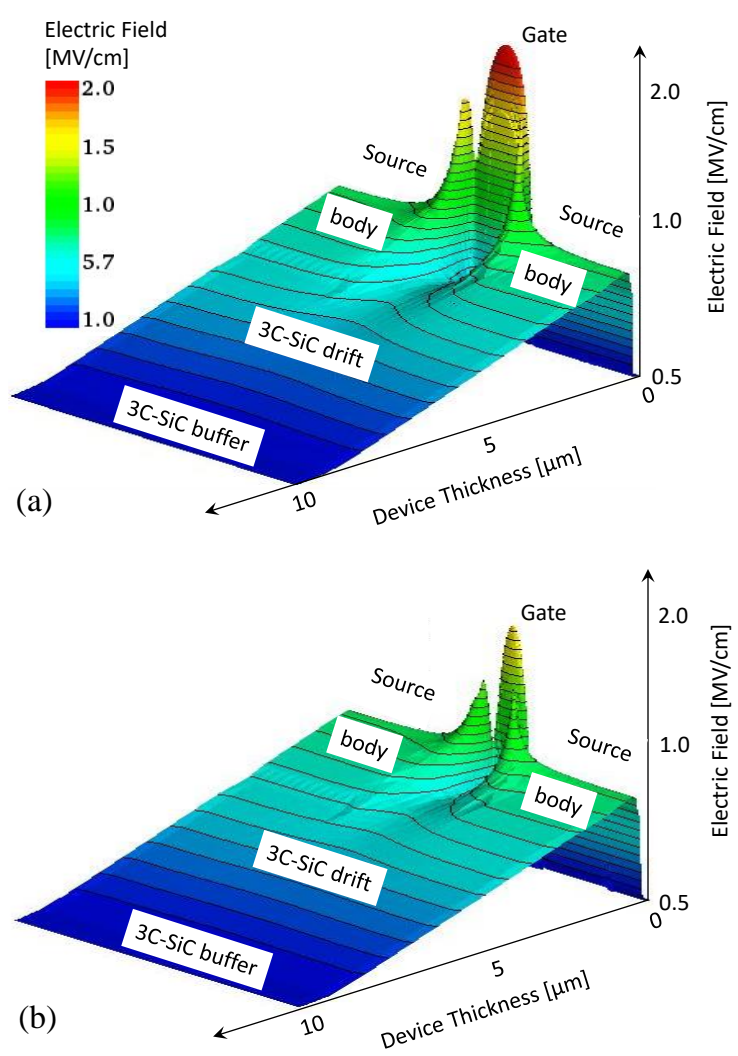

Fig. 8 Electric field plots at $\mathrm{T}=300 \mathrm{~K}$ for (a) Golden design without S-J JFET, (b) golden design featuring extended p-body edges forming a local S-J region.

Table III. Properties and performance of the simulated golden 3CSiC-on-Si S-J JFET MOSFET design.

\begin{tabular}{|c|c|c|c|c|}
\hline & & $\begin{array}{c}\text { Golden } \\
\text { design } \\
\text { having } \\
\text { S-J } \\
\text { JFET }\end{array}$ & $\begin{array}{c}\text { Golden } \\
\text { design } \\
\text { without } \\
\text { S-J } \\
\text { JFET }\end{array}$ & $\begin{array}{c}\text { Theoretical/ } \\
\text { Conventional } \\
\text { design }\end{array}$ \\
\hline \multicolumn{2}{|c|}{$\begin{array}{c}\text { Gate Oxide Thickness } \\
(\mathrm{nm})\end{array}$} & \multicolumn{3}{|c|}{60} \\
\hline \multicolumn{2}{|c|}{ Fixed Charges $\left(\mathrm{cm}^{-2}\right)$} & \multicolumn{3}{|c|}{$2.5 \times 10^{11}$} \\
\hline \multicolumn{2}{|c|}{$\begin{array}{c}\text { p-body doping } \\
\text { (gradual / stepped) }\end{array}$} & $\begin{array}{c}\text { Stepped } \\
\text { epitaxial }\end{array}$ & $\begin{array}{l}\text { Stepped } \\
\text { epitaxial }\end{array}$ & implanted \\
\hline \multicolumn{2}{|c|}{ Charge Imbalance (\%) } & -59 & - & - \\
\hline \multirow{2}{*}{$\begin{array}{l}\text { Breakdown } \\
\text { Voltage }(V)\end{array}$} & $\mathbf{T}=300 \mathrm{~K}$ & 688 & 387 & 734 \\
\hline & $\mathrm{T}=473 \mathrm{~K}$ & 790 & 530 & 810 \\
\hline \multirow{2}{*}{$\begin{array}{c}\text { Effective } \\
\text { Channel } \\
\text { Mobility } \\
\left(\mathrm{cm}^{2} \mathrm{Vs}^{-1}\right) \text { at } \\
\mathrm{V}_{\mathrm{G}}=10 \mathrm{~V}\end{array}$} & $\mathrm{~T}=300 \mathrm{~K}$ & 225 & 240 & 195 \\
\hline & $\mathrm{T}=473 \mathrm{~K}$ & 150 & 147 & 113 \\
\hline \multirow{2}{*}{$\begin{array}{l}\boldsymbol{R}_{\boldsymbol{D S}, \boldsymbol{o n}}(\mathrm{mOhms} \\
\left.* \mathrm{~cm}^{2}\right)\end{array}$} & $\mathrm{T}=300 \mathrm{~K}$ & 8.3 & 5.9 & 7.5 \\
\hline & $\mathrm{T}=473 \mathrm{~K}$ & 16 & 11.7 & 16.6 \\
\hline \multirow{2}{*}{$\begin{array}{l}\text { Threshold } \\
\text { Voltage }(V)\end{array}$} & $\mathrm{T}=300 \mathrm{~K}$ & 3.6 & 3.6 & 3.7 \\
\hline & $\mathrm{T}=\mathbf{4 7 3 K}$ & 3.4 & 3.4 & 3.5 \\
\hline
\end{tabular}

\section{Impact of partial overcompensation}

The overcompensation of in-situ doping with limited number of implantation steps can lead to the formation of thin p-type stripes of non-compensated regions remaining within the JFET. For as long as their thickness is smaller than the diffusion length $\left(L_{n}\right)$ of electrons, these stripes add to the onresistance but do not completely block the electrons flow. In example, two edge S-J JFET MOSFET variants are considered featuring a thin and a thick p-type stripe correspondingly in the JFET. In Fig. 9, the equilibrium state of the conduction bands is illustrated after solving the initial Poisson equations with the TCAD sDevice tool and the boundaries of each stripe are indicated with dashed lines.

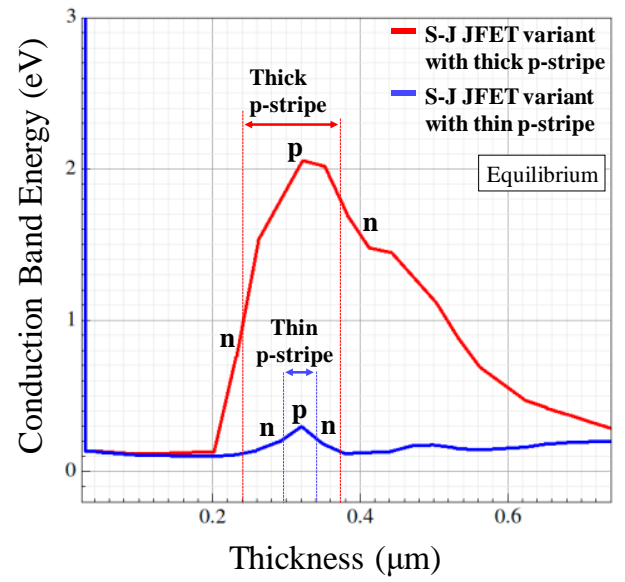

Fig. 9 Equilibrium state of a thick and a thin p-stripe in the over compensated JFET corresponding to design variants with $70 \%$ and $90 \%$ the dose values in Table I and a gradual p-body profile.

In Fig. 10, the MOSFETs are biased with $V_{G}=10 \mathrm{~V}$ and $V_{D}=20 \mathrm{~V}$, which are sufficient values to turn-on the particular devices. Under these conditions $\left(V_{G}>V_{t h}, V_{D}>\right.$ 0 ), the top n-p diode of the thin p-stripe becomes forward biased and minority electrons diffuse in the p-type region of the diode. The $L_{n}$ of electrons allows them to reach at the boundary of the depletion region of the reversed bias bottom p-n diode. The injected electrons, that are not recombined

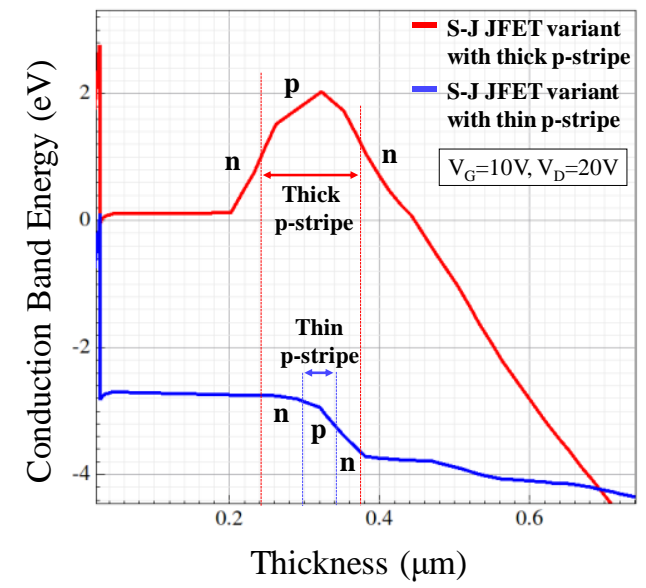

Fig. 10 Forward bias behaviour of a thick and a thin p-stripe in the over compensated JFET corresponding to design variants with $70 \%$ and $90 \%$ the dose values in Table I and a gradual p-body profile. 
within the hostile p-type environment, are accelerated to the n-type region because of the enhanced electric field at the space charge region of the $\mathrm{p}-\mathrm{n}$ diode. In consequence, in the $\mathrm{S}$-J JFET design variant with the thin $\mathrm{p}$-stripe, electrons are free to diffuse from left to the right direction. On the other hand, the n-p diode of the thick p-stripe, with the initially fully deployed built-in potential, still obstructs the free electrons' flow with a potential barrier, resulting in a largely increased $R_{D S, \text { on }}^{S p}$.

\section{E. Sensitivity to geometric variations}

The performance and the characteristics of the MOSFET devices following the proposed process flow, could become sensitive to the device dimensions. In this sub-section, the performance sensitivity is investigated by the means of the SJ edge length (ledge) and the channel length.

A first sensitivity analysis was carried out considering the S-J ledge as a design variable, whilst the channel length is considered constant (Fig. 11). Each simulated structure features a ledge which differs by delta $(d)$ with regards to the golden design, which is used as the reference design. The values of $d$ for this first analysis are assumed $-50 \%,-25 \%$, $+25 \%$ and $+50 \%$. In addition, the case of $d=-100 \%$ is also considered, which corresponds to the golden design without the S-J part. The simulated structures for this first sensitivity analysis are illustrated in Fig. 11, where the golden design corresponds to a $d$ value of $0 \%$.

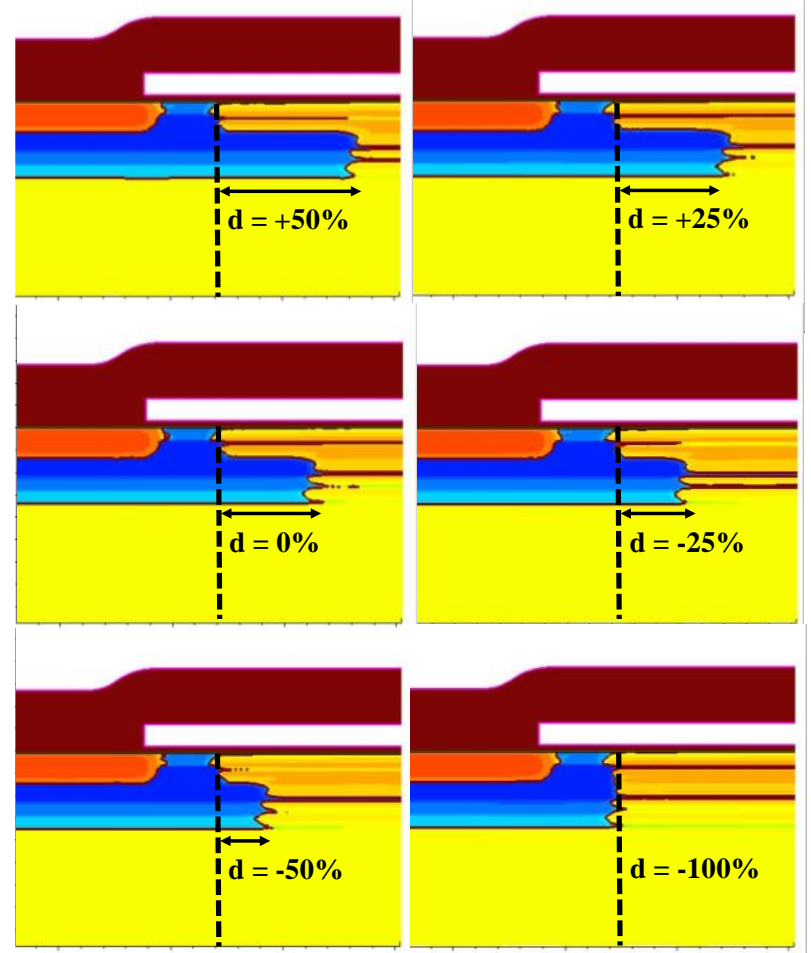

Fig. 11 A first performance sensitivity analysis considered varying the $\mathrm{S}$ J edge length by delta (d) in reference to the golden design.

The results are illustrated in Fig. 12 and in Table IV. For a variation of ledge by $+25 \%$ the $R_{D S, o n}^{s p}$ increases by $\sim 18 \%$ at $\mathrm{T}=300 \mathrm{~K}$ and by $\sim 16 \%$ at $\mathrm{T}=473 \mathrm{~K}$ whereas the breakdown voltage increases by $\sim 5 \%$ at $\mathrm{T}=300 \mathrm{~K}$ and by $\sim 2 \%$ at $\mathrm{T}=473 \mathrm{~K}$. For a variation of ledge delta by $-25 \%$ the impact is somewhat less; the $R_{D S, o n}^{s p}$ drops by $\sim 11 \%$ at $\mathrm{T}=300 \mathrm{~K}$ and by $\sim 9 \%$ at $\mathrm{T}=473 \mathrm{~K}$ whereas the breakdown voltage drops by $\sim 13 \%$ at $\mathrm{T}=300 \mathrm{~K}$ and by $\sim 10 \%$ at $\mathrm{T}=473 \mathrm{~K}$. It is therefore safe to conclude that the impact of ledge variation is small on the breakdown voltage (smaller than $\sim 13 \%$ for $25 \%$ variation) whereas the impact on $R_{D S, \text { on }}^{s p}$ is at least better than proportional to the variation exhibited (smaller than $\sim 18 \%$ for $25 \%$ variation).

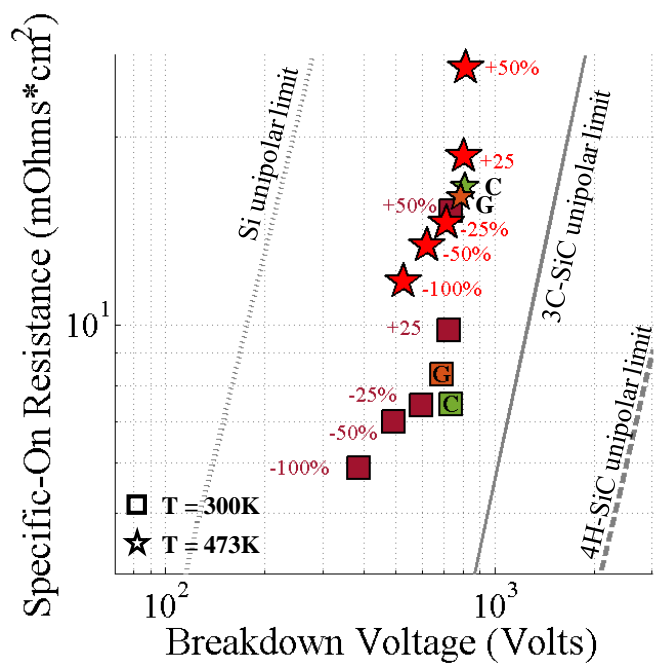

Fig. 12 The $R_{D S, \text { on }}^{s p}$ as a function of blocking voltage for simulated structures with the S-J edge length changing by delta (d), with regards to the golden design, and for various temperatures.

Table IV. Performance sensitivity as a function of S-J edge length.

\begin{tabular}{|c|c|c|c|c|c|}
\hline \multirow{2}{*}{$\begin{array}{c}\text { Ledge } \\
\text { delta (d) } \\
\text { compared } \\
\text { to Golden } \\
\text { Design } \\
(\%)\end{array}$} & \multirow{2}{*}{$\begin{array}{c}\text { Charge } \\
\text { Imbalance } \\
(\%)\end{array}$} & \multicolumn{2}{|c|}{$\begin{array}{l}\text { Breakdown } \\
\text { Voltage }(V) \\
\end{array}$} & \multicolumn{2}{|c|}{$\begin{array}{c}\boldsymbol{R}_{\boldsymbol{D S}, \boldsymbol{o n}} \\
\left(m O h m s * \mathrm{~cm}^{2}\right)\end{array}$} \\
\hline & & $300 \mathrm{~K}$ & $473 K$ & $300 K$ & $473 K$ \\
\hline $\begin{array}{c}-100 \% \\
\text { (Golden } \\
\text { without } \\
\text { S-J part) } \\
\end{array}$ & - & 387 & 530 & 5.9 & 11.7 \\
\hline$-50 \%$ & -216 & 493 & 624 & 7 & 13.4 \\
\hline$-25 \%$ & -111 & 598 & 713 & 7.4 & 14.5 \\
\hline $\begin{array}{c}0 \% \\
\text { (Golden } \\
\text { Design) }\end{array}$ & -59 & 688 & 790 & 8.3 & 16 \\
\hline$+25 \%$ & -10 & 723 & 805 & 9.8 & 18.6 \\
\hline$+50 \%$ & 13 & 737 & 817 & 15.2 & 25.7 \\
\hline
\end{tabular}

A second sensitivity analysis was carried out considering the channel length as variable, whilst the S-J ledge considered constant (Fig. 13). The results are shown in Fig. 14 and Table $\mathrm{V}$. The impact of channel length on $R_{D S, \text { on }}^{s p}$ and the breakdown voltage is small; for $25 \%$ variation the impact on $R_{D S, \text { on }}^{S p}$ is $\sim 2 \%$ or less and the impact on breakdown voltage is $\sim 4 \%$ or less. This performance is significantly better than what is 
expected from a conventional design (no edge extension of body). This is because a variation in the channel length with ledge kept constant does not change the minimum distance between the two p-body regions of the MOSFET. The latter is not the case in conventionally designed devices. It is hence safe to conclude that the extended body regions help to decouple the channel length from the important performance parameters of $R_{D S, \text { on }}^{S p}$ and breakdown voltage.
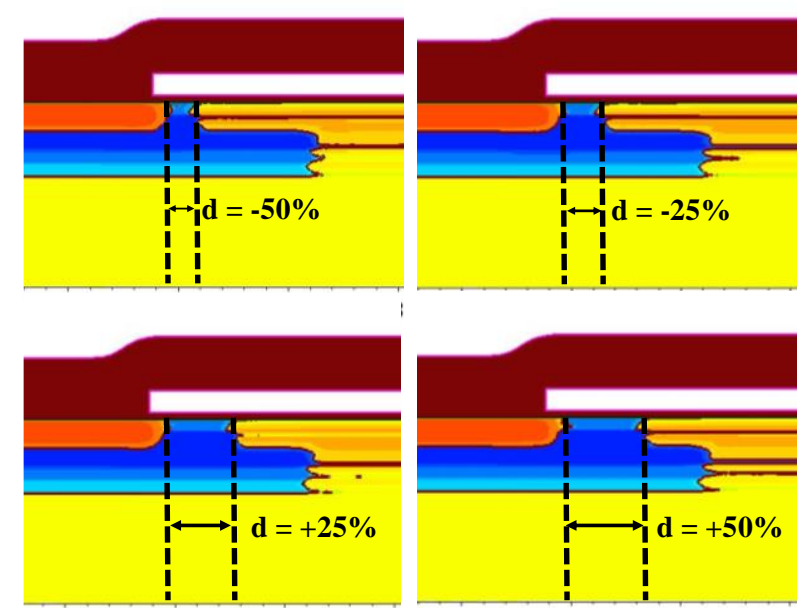

Fig. 13 The $R_{D S, \text { on }}^{s p}$ as a function of blocking voltage for simulated structures with the S-J edge length changing by delta (d), with regards to the golden design, and for various temperatures.

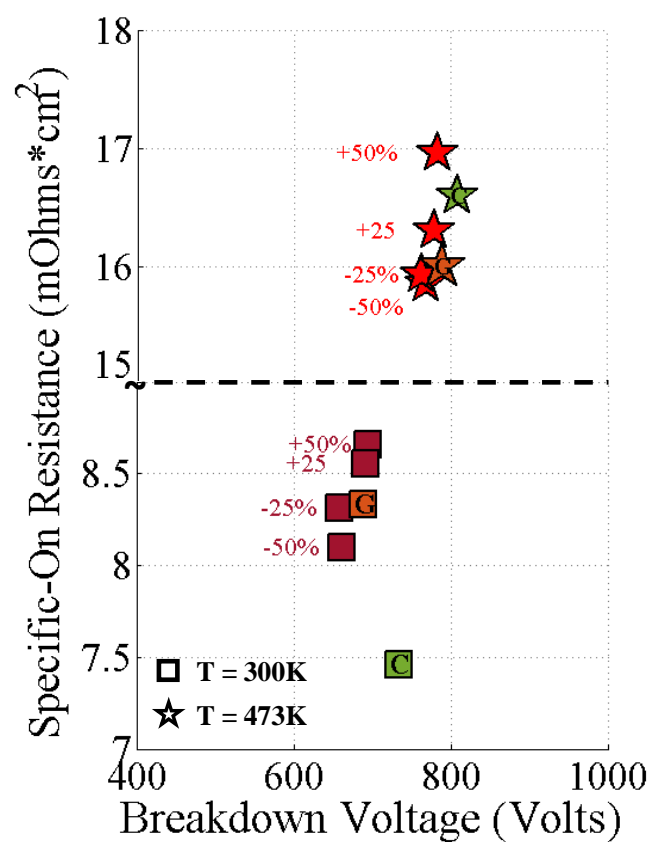

Fig. 14 The $R_{D S, o n}^{s p}$ as a function of blocking voltage for simulated structures with the channel length changing by delta (d), with regards to the golden design, and for various temperatures.

\section{CONCLUSIONS}

In this paper a novel S-J JFET process for viable vertical 3C-SiC-on-Si n-MOSFETs is proposed, disrupting current material related limitations. Instead of utilizing ion
Table V. Performance sensitivity as a function of channel length

\begin{tabular}{|c|c|c|c|c|c|}
\hline \multirow{2}{*}{$\begin{array}{c}\text { Channel } \\
\text { length delta } \\
\text { compared to } \\
\text { Golden } \\
\text { Design }(\%) \\
\end{array}$} & \multirow{2}{*}{$\begin{array}{c}\text { Charge } \\
\text { Imbalance } \\
(\%)\end{array}$} & \multicolumn{2}{|c|}{$\begin{array}{l}\text { Breakdown } \\
\text { Voltage }(V)\end{array}$} & \multicolumn{2}{|c|}{$\begin{aligned} & \boldsymbol{R}_{\boldsymbol{D S}, \boldsymbol{o n}} \\
&(\mathrm{mOhms} \\
&\left.* \mathrm{~cm}^{2}\right)\end{aligned}$} \\
\hline & & $300 K$ & $473 K$ & $300 K$ & $473 K$ \\
\hline$-50 \%$ & -29 & 662 & 770 & 8.09 & 15.85 \\
\hline$-25 \%$ & -45 & 658 & 764 & 8.31 & 15.93 \\
\hline $\begin{array}{c}0 \% \\
\text { (Golden } \\
\text { Design) }\end{array}$ & -59 & 688 & 790 & 8.32 & 16 \\
\hline$+25 \%$ & -80 & 691 & 780 & 8.55 & 16.3 \\
\hline$+\mathbf{5 0 \%}$ & -92 & 695 & 785 & 8.66 & 16.96 \\
\hline
\end{tabular}

implantation to form the p-body region, a thin layer of p-type conductivity can be grown by homo-epitaxy. Thereafter, a JFET region with localised S-J region can be created via $\mathrm{N}$ implants which overcompensate the p-type layer in a nonuniform manner. To assess the proposed MOSFET fabrication method and design it was important to develop and validate a channel mobility degradation model for $3 \mathrm{C}$ $\mathrm{SiC}$ MOS structures which takes into consideration the weighted degradation contribution due to doping level $\left(\mu_{d o p}^{3 C-S i C}\right)$, electric field $\left(\mu_{E / /}^{3 C-S i C}\right)$, scattering phenomena and temperature. By implementing the model in TCAD a relatively wide safe charge imbalance window, from $-65 \%$ up to $-45 \%$, was identified which can accommodate for uncertainties in the final net doping concentration value. Further, the proposed design was shown to have relatively small sensitivity to variations in channel length and the length of the S-J region. The golden design, following the S-J JFET process, not only enables the 3C-SiC-on-Si MOSFET technology, but also has the potential to offer excellent onstate, high channel mobility values and forward blocking capabilities for a wide range of temperatures $(300 \mathrm{~K} \leq T \leq$ $473 \mathrm{~K})$, similar to the theoretical design method for MOSFETs. The proposed process could be applicable on any WBG material technology which experiences limited p-type implants activation.

\section{REFERENCES}

[1] A. A. Lebedev, S. P. Lebedev, V. Y. Davydov, S. N. Novikov, and Y. N. Makarov, "Growth and investigation $\mathrm{SiC}$ based heterostructures," in 15th Biennial Baltic Electronics Conference (BEC), 2016, pp. 5-6.

[2] T. Tachibana, H. S. Kong, Y. C. Wang, and R. F. Davis, "Hall measurements as a function of temperature on monocrystalline $\mathrm{SiC}$ thin films," J. Appl. Phys., vol. 67, no. 6375, 1990.

[3] H. Nagasawa, K. Yagi, T. Kawahara, and N. Hatta, "Properties of Free-Standing 3C-SiC Monocrystals grown on Undulant- Si ( 001 ) Substrate," vol. 436, pp. 3-8, 2003.

[4] H. Nagasawa et al., "Low-Defect 3C-SiC Grown on Undulant-Si (001) Substrates," in Silicon Carbide Recent Major Advances, W. J. Choyke, H. Matsunami, and G. Pensl, Eds. Berlin: Springer, 2004.

[5] B. A. Schöner, M. Krieger, G. Pensl, M. Abe, and H. Nagasawa, 
"Fabrication and Characterization of 3C-SiC-Based MOSFETs," pp. 523-530, 2006.

[6] B. Van Zeghbroeck and H. Fardi, "Comparison of 3C-SiC and 4HSiC Power MOSFETs," vol. 924, pp. 774-777, 2018.

[7] M. Bakowski, "Status and Prospects of SiC Power Devices Status and Prospects of SiC Power Devices," IEEJ Trans. Ind. Appl., vol. 126, no. 4, pp. 391-399, 2006

[8] M. Krieger, G. Pensl, M. Bakowski, and A. Schöner, "Hall Effect in the Channel of 3C-SiC MOSFETs," Mater. Sci. Forum, vol. 485, pp. 441-444, 2005.

[9] J. Wan, M. A. Capano, M. R. Melloch, and J. A. Cooper, "N-channel 3C-SiC MOSFETs on silicon substrate," IEEE Electron Device Lett., vol. 23, no. 8, pp. 482-484, 2002.

[10] T. O. Hshima et al., "The Electrical Characteristics of Metal-OxideSemiconductor Field Effect Transistors Fabricated on Cubic Silicon Carbide,” Jpn. J. Appl. Phys., vol. 42, 2003.

[11] K. K. Lee et al., "N-Channel MOSFETs Fabricated on HomoepitaxyGrown 3C-SiC Films," IEEE Electron Device Lett., vol. 24, no. 7, pp. 466-468, 2003.

[12] A. Schöner et al., "Realisation of Large Area 3C-SiC MOSFETs," Mater. Sci. Forum, vol. 483-485, pp. 801-804, 2005.

[13] M. Abe et al., "High current capability of 3C-SiC vertical DMOSFETs," Microelectron. Eng., vol. 83, no. 1 SPEC. ISS., pp. 24-26, 2006

[14] M. Bakowski et al., "Development of 3C-SiC MOSFETs," J. Telecommun. Inf. Technol., pp. 49-56, 2007.

[15] H. Search, C. Journals, A. Contact, M. Iopscience, and I. P. Address, "High-Temperature Operation of Silicon Carbide MOSFET," vol. 310 .

[16] E. Sakuma, H. Daimon, and M. Yamanaka, "Experimental 3C-Sic MOSFET," vol. 1, no. 7, pp. 404-406, 1986.

[17] H. Nagasawa, M. Abe, K. Yagi, T. Kawahara, and N. Hatta, "Fabrication of high performance 3C-SiC vertical MOSFETs by reducing planar defects," Phys. status solidi, vol. 1280, no. 7, pp. 1272-1280, 2008

[18] H. Nagasawa, K. Yagi, T. Kawahara, N. Hatta, and M. Abe, "Heteroand homo-epitaxial growth of 3C-SiC for MOS-FETs," Microelectron. Eng., vol. 83, pp. 185-188, 2006.

[19] H. Search, C. Journals, A. Contact, M. Iopscience, and I. P. Address, "Band alignment and defect states at $\mathrm{SiC} /$ oxide," vol. 1839.

[20] F. Ciobanu, G. Pensl, V. Afanas, and A. Schöner, "Low Density of Interface States in n-type 4H-SiC MOS Capacitors Achieved by Nitrogen Implantation,” Mater. Sci. Forum, vol. 485, pp. 693-696, 2005.

[21] A. Arvanitopoulos, N. Lophitis, K. N. Gyftakis, S. Perkins, and M. Antoniou, "Validated physical models and parameters of bulk $3 \mathrm{C}-\mathrm{SiC}$ aiming for credible technology computer aided design (TCAD) simulation," Semicond. Sci. Technol., vol. 32, no. 10, p. 104009, 2017.

[22] F. Li et al., "Electrical activation of nitrogen heavily implanted 3CSiC(1 0 0)," Appl. Surf. Sci., vol. 353, no. October 2015, pp. 958-963, 2015.

[23] T. Kimoto, K. Kawahara, and H. Niwa, "Ion implantation technology in $\mathrm{SiC}$ for power device applications," Junction Technol. ( ..., no. V, pp. 4-9, 2014.

[24] M. V. Rao et al., "Al and B ion-implantations in 6H- and 3C-SiC," $J$. Appl. Phys., vol. 77, no. 6, pp. 2479-2485, 1995.

[25] L. Wang et al., "Demonstration of p-type 3CSiC grown on $150 \mathrm{~mm}$ $\mathrm{Si}\left(\begin{array}{lll}1 & 0 & 0\end{array}\right)$ substrates by atomic-layer epitaxy at $1000^{\circ} \mathrm{c}, " \mathrm{~J}$. Cryst. Growth, vol. 329, no. 1, pp. 67-70, 2011.

[26] A. Arvanitopoulos, N. Lophitis, K. N. Gyftakis, S. Perkins, and M. Antoniou, "Validated physical models and parameters of bulk 3C-SiC aiming for credible Technology Computer Aided Design ( TCAD ) simulation," IOP Semicond. Sci. Technol., vol. 32, no. 10, p. 104009 , Oct. 2017.

[27] N. Lophitis, A. Arvanitopoulos, S. Perkins, and M. Antoniou, "TCAD Device Modelling and Simulation of Wide Bandgap Power Semiconductors," in Disruptive Wide Bandgap Semiconductors, Related Technologies, and Their Applications, Y. K. Sharma, Ed. Rijeka: InTech, 2018.

[28] A. Arvanitopoulos et al., "Viable 3C-SiC-on-Si MOSFET design disrupting current Material Technology Limitations," in IEEE 12th
International Symposium on Diagnostics for Electrical Machines, Power Electronics and Drives (SDEMPED), 2019, pp. 364-370.

[29] P. Ward, N. Lophitis, T. Trajkovic, and F. Udrea, "High voltage semiconductor devices," US 20170243937, Aug-2017.

[30] Jianwei Wan, M. A. Capano, M. R. Melloch, and J. A. J. Cooper, "Inversion channel MOSFETs in 3C-SiC on silicon," Proceedings. IEEE Lester Eastman Conf. High Perform. Devices, no. Cvd, pp. 8389, 2002.

[31] Synopsys, "Sentaurus TM Structure Process User Guide.," 2017.

[32] T. Kimoto, "Updated trade-off relationship between specific onresistance and breakdown voltage in $4 \mathrm{H}-\mathrm{SiC}\{0001\}$ unipolar devices," Jpn. J. Appl. Phys., vol. 58, no. 018002, 2018.

[33] A. Arvanitopoulos et al., "On the Suitability of 3C-Silicon Carbide as an Alternative to 4H-Silicon Carbide for Power Diodes," IEEE Trans. Ind. Appl., vol. 55, no. 4, pp. 4080-4090, 2019.

[34] F. Roccaforte et al., "Challenges for energy efficient wide band gap semiconductor power devices," Phys. status solidi, vol. 211, no. 9, pp. 2063-2071, 2014. 